\title{
Satisfactory Control for Glucose Profile by Combined Agents of Xultophy with A Small Dose
}

\author{
Hiroshi Bando ${ }^{1,2,3^{*}}$, Hiroko Ogawa ${ }^{3}$, Shinji Nagahiro ${ }^{3}$, Miwako Nakanishi ${ }^{3}$, Osami Watanabe ${ }^{3}$ \\ ${ }^{1}$ Medical Research/Tokushima University, Tokushima, Japan \\ ${ }^{2} J a p a n$ Low Carbohydrate Diet Promotion Association (JLCDPA), Kyoto, Japan \\ ${ }^{3}$ Yoshinogawa Hospital, Tokushima, Japan
}

Corresponding Author: Hiroshi BANDO, MD, PhD, FACP ${ }^{\text {ORCID iD }}$

Address: Tokushima University /Medical Research, Nakashowa 1-61, Tokushima 770-0943, Japan. Email: pianomed@bronze.ocn.ne.jp

Received date: 16 April 2021; Accepted date: 30 May 2021; Published date: 08 June 2021

Citation: Bando H, Ogawa H, Nagahiro S, Nakanishi M, Watanabe O. Satisfactory Control for Glucose Profile by Combined Agents of Xultophy with A Small Dose. Diab Res Open Access. 2021 Jun 08;3(2):23-29.

Copyright (C) 2021 Bando H, Ogawa H, Nagahiro S, Nakanishi M, Watanabe O. This is an open-access article distributed under the Creative Commons Attribution License, which permits unrestricted use, distribution, and reproduction in any medium, provided the original work is properly cited.

\begin{abstract}
The patient was a 74-year-old female with type 2 diabetes mellitus (T2DM) treated on Humalog mix 25 twice a day. As social history, she has worked long years for growing and harvesting lotus roots. It gives physically heavy loading, which brings unstable glycemic daily control. She had to titrate minute regulation every time. For stable glucose variability, the treatment was changed to Xultophy, which is a specific combined agent of Insulin Degludec and Liraglutide (IDeg/Lira) once a day. Then, detailed glucose monitoring showed a better daily profile of blood glucose, irrespective of heavy or light work. It showed the bio-psychosocial benefit of Xultophy.
\end{abstract}

\section{Keywords}

Xultophy, Insulin Degludec and Liraglutide, Humalog Mix 25, Type 2 Diabetes Mellitus, Bio-Psycho-Social

\author{
Abbreviations \\ IDeg/Lira: Insulin Degludec and Liraglutide; T2DM; Type 2 Diabetes Mellitus; LCD: Low Carbohydrate Diet; \\ CR: Calorie Restriction
}

\section{Introduction}

In recent decades, diabetes has been more prevalent worldwide. The principles of adequate therapy for diabetes include nutritional therapy, exercise, and pharmacological treatment [1]. Several guidelines for diabetes have been proposed so far [2]. In 2021, American Diabetes Association (ADA) presented a new standard method for adequate diagnosis and treatment for diabetes [3]. The therapeutic perspectives have to be considered from macroangiopathic and microangiopathic points of view [4]

As regards to diabetic therapy, nutritional therapy is a fundamental principle. Formerly, the standard method was Calorie Restriction (CR), which means decreasing intake of fatty food. After that, a variety of health care and medical care have brought the changes into a Low Carbohydrate Diet (LCD). LCD means the restriction of the amount of carbohydrate, irrespective of taking fatty or high-calorie foods. LCD was begun by 
Dr. Atkins et al., in European and western countries [5]. The clinical effect of LCD has been prevalent for long with several pieces of evidence $[6,7]$. In contrast, the authors and co-researchers in Japan have initiated LCD and developed LCD movements so far [8]. In order to make LCD understood in broad fields, we have established a newly Japan LCD Promotion Association (JLCDPA). Successively, we tried to make various chances to develop LCD socially, medically, and educationally using books, seminars, and workshops [9]. When people can apply LCD in their daily lives, three kinds of LCD are recommended. They are petiteLCD, standard-LCD, and super-LCD, which contain carbohydrate in calorie ratio as $40 \%, 26 \%$, and $12 \%$, respectively [10]. In addition, a variety of researches have been continued including continuous glucose monitoring (CGM), meal tolerance test (MTT), insulinogenic index (IGI), a daily profile of blood variability, Morbus (M) value, and actual use and combined agents of Xultophy [11].

From a pharmacological point of view, various types of hypoglycemic agents were applied for long. Some are oral hypoglycemic agents (OHAs) and others are injectable agents [12]. The latter includes some kinds of glucagon like peptide-1 receptor agonists (GLP1Ras), such as liraglutide, exenatide, dulaglutide, lixisenatide, and so on [13]. Related to several research for GLP-1RAs, clinically useful evaluation has summarized by the Network Meta-Analysis (NMA) for better glycemic control as well as research outcomes of cardiovascular disease (CVD) [14]. Consequently, beneficial cardiometabolic efficacy has been observed for applying GLP-1Ras.

Among several GLP-1Ras, liraglutide has been known and used broadly for patients with type 2 diabetes mellitus (T2DM). After lots of practice and research, Xultophy was produced as the combined agents of insulin degludec and liraglutide (IDeg/Lira) [15]. Insulin degludec has a role of basal insulin, which provides the decreased fasting blood glucose. GLP-1Ra gives the decreased levels of pre-prandial and postprandial glucose [16]. The combination of these agents with an ideal fixed ratio would make improved glucose variability by providing only one injection a day. In fact, Xultophy showed various studies with improved efficacy of glucose control in comparison with the result of one agent [17]. Furthermore, it has a beneficial effect of cardioprotective mechanism by elevating the endocrinological function of $\beta$-cell of the pancreas [18].

The authors and co-researchers have continued practice and several reports concerning diabetes and related treatments. Among these clinical experiences, an older female patient with T2DM showed impressive progress. She received formerly insulin therapy twice a day, and her glycemic control was rather unstable. When the treatment was changed to Xultophy with one injection, her lifestyle became satisfactory with less psychological and social stresses. Her clinical course and some perspective from bio-psycho-social points of view will be described in this article.

\section{Case Report}

\section{Medical History:}

The patient was pointed out to have T2DM and hypothyroidism about 20 years ago. For her treatment, she was initially given OHAs and levothyroxine $50 \mu \mathrm{g}$ 1T per day. Successively, insulin treatment was initiated about 10 years ago. She was treated for hemorrhoid 8 years ago. On Nov 2018, laboratory data showed that $\mathrm{Hb} 11.6 \mathrm{~g} / \mathrm{dL}$ and $\mathrm{MCV}$ value dropped from 87.3 to 81.8 , suggesting the possibility of anemia and bleeding of gastro-intestinal and colon. The endoscopic examination for upper and lower GI tracts showed no significant changes for bleeding foci.

From 2019 to 2021, she has been treated on Humalog Mix 25 twice daily as an insulin treatment for her diabetes. She has been working hard every day as a farmer, growing and harvesting lotus roots. She has continued self-monitoring blood glucose three times a day and constantly adjusted her insulin dose. From Dec 2020, she felt some difficulty in proper glycemic control, and then the treatment was changed from insulin to once-daily Xultophy.

\section{Current Physicals \& Exams:}

Consciousness is alert, and speech is normal without abnormality. Vitals are normal including pulse BP, respiration, and $\mathrm{SpO} 2$ level. Physicals are within 
Citation: Bando H, Ogawa H, Nagahiro S, Nakanishi M, Watanabe O. Satisfactory Control for Glucose Profile by Combined Agents of Xultophy with A Small Dose. Diab Res Open Access. 2021 Jun 08;3(2):23-29.

normal limits such as body mass index (BMI), lung heart, and abdomen. Neurological findings are negative for diabetic neuropathy.

Several fundamental laboratory data are as follows: Hb 11.2 g/dL、RBC $359 \times 10^{6} / \mu \mathrm{L} 、$ Ht 35.9\% 、 MCV 87.3 $\mathrm{fL}(80-98) 、 \mathrm{MCH}$ 27.3pg (27-34)、MCHC $31.2 \mathrm{~g} / \mathrm{dL}$ (31-36) 、WBC $4200 / \mu \mathrm{L}$ 、Plt $20.9 \times 10^{4} / \mu \mathrm{L}, \mathrm{BUN} 18$ $\mathrm{mg} / \mathrm{dL} 、 \mathrm{Cr} 0.7 \mathrm{mg} / \mathrm{dL}$, uric acid $2.2 \mathrm{mg} / \mathrm{dL}$ 、 eGFR 70.2 $\mathrm{mL} / \mathrm{min} / 1.73 \mathrm{~m}^{2}$ 、TG $61 \mathrm{mg} / \mathrm{dL}$ 、HDL-C $83 \mathrm{mg} / \mathrm{dL}$ 、 LDL-C 76 mg/dL、TC 180 mg/dL、TP 7.1 g/dL、AST 26 U/L、ALT 10 U/L、Y-GT 25 U/L、ALP 359 U/L (203460)、LDH 324 U/L(100-340)、T-Bil $0.6 \mathrm{mg} / \mathrm{dL}$ 、 amylase $128 \mathrm{U} / \mathrm{L}(35-125) 、 \mathrm{CRP} \quad 0.04 \mathrm{mg} / \mathrm{dL}, \mathrm{HbA} 1 \mathrm{c}$ $8.0 \%$, fasting blood glucose $189 \mathrm{mg} / \mathrm{dL}$ 、
Other exams are included in the following:

1. Chest X-ray and ECG showed unremarkable

2. Ophthalmic test was negative for retinopathy

3. Vascular extensibility test showed Anklebrachial index (ABI) 1.12/1.12. cardio-ankle vascular index (CAVI) 8.8/8.6.

\section{Result}

The changes in major laboratory findings over the last few years are shown in Table-1. HbA1c level has been recently on a slight upward trend. The value of hemoglobin $(\mathrm{Hb})$ did not change, and the MCV value dropped to 81 once in Nov 2018, but otherwise, MCV was stable. In addition, there were no changes in liver function, lipids, CRP, and others.

\begin{tabular}{|l|c|c|c|c|c|c|c|c|}
\hline \multicolumn{7}{|c|}{ Table-1: Changes in fundamental biomarkers } \\
\hline & \multicolumn{2}{|c|}{2017} & \multicolumn{2}{|c|}{$\mathbf{2 0 1 8}$} & $\mathbf{2 0 1 9}$ & \multicolumn{2}{c|}{$\mathbf{2 0 2 0}$} & 2021 \\
\cline { 2 - 11 } & July & Nov & May & Nov & June & Feb & Sept & Feb \\
\hline HbA1c (\%) & 7.7 & 7.5 & 7.8 & 7.4 & 7.8 & 7.9 & 8.0 & 8.0 \\
\hline glucose (mg/dL) & 148 & 105 & 148 & 202 & 182 & 244 & 145 & 252 \\
\hline Hb (g/dL) & 9.7 & 12.1 & 11.4 & 11.6 & 11.3 & 11.5 & 11.4 & 11.2 \\
\hline MCV (fL) & 89.3 & 87.8 & 87.3 & 81.8 & 93 & 91.8 & 84.8 & 87.3 \\
\hline WBC (/mcL) & 4500 & 4400 & 4000 & 3600 & 3000 & 4500 & 3700 & 4200 \\
\hline AST (IU/L) & 23 & 22 & 19 & 21 & 29 & 26 & 25 & 26 \\
\hline LDL (IU/L) & 126 & 130 & 111 & 121 & 129 & 126 & 119 & 126 \\
\hline CRP (mg/dL) & 0.05 & - & 0.04 & - & 0.02 & - & 0.04 & - \\
\hline
\end{tabular}

From Feb 2021, the treatment for diabetes was changed. Formerly, Humalog mix 25 was administered twice a day, but it was changed to Xultophy once-daily injection. Table-2 shows the details of the changes in the daily profile of blood glucose. Among them, on Days -1 to -5 , self-blood glucose measurement was performed three times a day, and the units of Humalog mix 25 was adjusted. For days 1 to 3, we started with Xultophy from 6, 8, 10 doses. Since blood glucose dropped to $59 \mathrm{mg} / \mathrm{dL}$ in the evening of day 5 , the unit was set to 9 doses from the next day. On days 11-16, blood glucose was measured 3 times a day on both pre-prandial and $60 \mathrm{~min}$ post-prandial time. Blood glucose 60 minutes after breakfast was over
$200 \mathrm{mg} / \mathrm{dL}$ in $4 / 5$. On the other hand, 60 minutes after lunch and 6o minutes after dinner, a total of 12 times (12/12) were within the range of 123-175 mg / dL. After day 17, her Xultophy doses were stable at 7-8 doses.

\section{Problems and Prescriptions}

From the above, the current medical problems can be summarized as follows:

1. T2DM: The medical history has 20 years, and no particularly remarkable microangiopathy or macroangiopathy is observed.

2. Treatment of T2DM: Insulin on Humalog mix 25 
Citation: Bando H, Ogawa H, Nagahiro S, Nakanishi M, Watanabe O. Satisfactory Control for Glucose Profile by Combined Agents of Xultophy with A Small Dose. Diab Res Open Access. 2021 Jun o8;3(2):23-29.

twice was changed to Xultophy once a day.

3. Hypothyroidism: Medical history has 20 years, which is stable with the administration of levothyroxine.

4. GERD: Grade D (reflux esophagitis).

5. Social status: Her occupation has been a farmer, which has been hard work outside. Consequently, she has checked blood glucose three times a day for long, in order to titrate the adequate insulin doses.

For the related problems mentioned above, the prescription was as follows: i) Metformin $\left(\right.$ Metogluco $^{\circledR}$ ) 50omg, ii) levothyroxine (Thyradin $S^{\circledR}$ ) 50 mcg 1T, iii) Lansoprazole (Takepron ${ }^{\circledR}$ ) $15 \mathrm{mg} 1 \mathrm{~T}$, iv) linagliptin $\left(\right.$ Trazenta $\left.^{\circledR}\right)$ 5mg $1 \mathrm{~T}$. After starting Xultophy, prescription i) to iii) were continued, and iv) was discontinued.

\begin{tabular}{|c|c|c|c|c|c|c|c|c|}
\hline \multicolumn{9}{|c|}{ Table-2: Changes in Blood Glucose } \\
\hline \multirow[t]{2}{*}{ Day } & \multicolumn{6}{|c|}{ Blood Glucose } & \multirow{2}{*}{$\begin{array}{c}\text { Mix } 25 \\
\text { Morning/Evening }\end{array}$} & \multirow{2}{*}{ Xultophy Dose } \\
\hline & Morning & $1 \mathrm{hr}$ & Noon & 1hr & Evening & 1hr & & \\
\hline-5 & 76 & & 101 & & 148 & & $8--9$ & \\
\hline-4 & 140 & & 133 & & 153 & & $8--9$ & \\
\hline-3 & 115 & & 128 & & 193 & & $8--9$ & \\
\hline-2 & 132 & & 135 & & 119 & & 8--9 & \\
\hline-1 & 103 & & 81 & & 208 & & $8--9$ & \\
\hline 1 & 113 & & 128 & & 153 & & & 6 \\
\hline 2 & 114 & & 171 & & 129 & & & 8 \\
\hline 3 & 130 & & 138 & & 73 & & & 10 \\
\hline 4 & 116 & & 110 & & 86 & & & 10 \\
\hline 5 & 117 & & 61 & & 59 & & & 10 \\
\hline 6 & 109 & & 119 & & 167 & & & 9 \\
\hline 7 & 111 & & 153 & & 135 & & & 9 \\
\hline 8 & 82 & & 152 & & 65 & & & 9 \\
\hline 9 & 98 & & 96 & & 62 & & & 9 \\
\hline 10 & 106 & & 64 & & 74 & & & 9 \\
\hline 11 & 115 & & 75 & 143 & 61 & 117 & & 8 \\
\hline 12 & 79 & 128 & 53 & 175 & 128 & 145 & & 8 \\
\hline 13 & 105 & 246 & 120 & 138 & 92 & 150 & & 8 \\
\hline 14 & 131 & 273 & 69 & 170 & 84 & 155 & & 8 \\
\hline 15 & 113 & 274 & 150 & 173 & 65 & 142 & & 8 \\
\hline 16 & 89 & 264 & 89 & 123 & 73 & 171 & & 8 \\
\hline 17 & 125 & & 103 & & 123 & & & 7 \\
\hline 18 & 140 & & 57 & & 89 & & & 7 \\
\hline 19 & 144 & & & & 83 & & & 7 \\
\hline 20 & 153 & & 164 & & 93 & & & 7 \\
\hline 25 & 120 & & 166 & & 90 & & & 7 \\
\hline 30 & 155 & & 108 & & 69 & & & 8 \\
\hline 35 & 125 & & 104 & & 81 & & & 7 \\
\hline
\end{tabular}




\section{Discussion}

From a historical point of view, diabetic treatment was developed using several OHAs and a few types of injections including insulin and GLP-1Ra. In order to get a better glucose profile, insulin therapy was proposed as a basal-bolus regimen [12]. Consequently, multiple daily injection (MDI) has been recognized for recommended strategy. Indeed, it is rather ideal to continue MDI, but multiple injections require much loading to a patient and also family. Recently, Xultophy was introduced to clinical practice, which is a convenient and effective way of treatment [15].

As regards to Xultophy, consecutive investigation of clinical efficacy was found. It has been the European Xultophy Treatment Retrospective Audit, which is usually called as EXTRA. The related investigation would be a real-word evidence (RWE) study (EXTRA) where data are from many diabetes centers in European countries [19]. The result revealed that HbA1c was significantly decreased by $0.7 \%$, and weight was decreased by $2.4 \mathrm{~kg}$, when treatment was changed from MDI to Xultophy for half year. The subjects of EXTRA study included 5 countries with > 600 patients. As a result, the initiation therapy caused HbA1c value $-0.9 \%$ significantly for half year [20]. From mentioned above, Xultophy is evaluated to have not only remarkable efficacy but also beneficial and useful regular lifestyle for diabetic patient and also the family.

In this current case, diabetic treatment was changed from Humalog mix 25 twice a day to Xultophy once a day. The initial amount was 6 doses. According to the standard regimen of Xultophy, the start dose would be 16 doses in the case of previously treated on insulin, and 10 doses for naive case of insulin [16]. However, different circumstances may exist among European, North American, Eastern or Asian countries. Authors reported a diabetic case treated by Xultophy with smaller doses than usual [21]. Current case has changed the Xultophy doses from 6 to 10, and after that 7 or 8 finally, which were smaller doses. This characteristic point may be the synergy effect of combined agents of Xultophy [16]. Other reasons may be from the specific background of the patients.
They are i) older age, ii) long diabetic period, and iii) physically hard working every day.

In this current investigation, detailed feedback and impression were obtained from the patient herself. Several perspectives regarding the response and efficacy of Xultophy are found. They are i) postprandial blood glucose did not rise so much as expected compared to before, ii) when eating snacks at night, glucose in next morning was not so higher than expected, iii) pre-prandial glucoses on noon and evening after hard working is not so low as expected, iv) For hypoglycemic period, the falling speed of glucose is slower than before, v) In the case of hypoglycemia with the same glucose level, the symptoms that the body feels are milder than before. From mentioned above, Xultophy seems to have clinically beneficial effects in the light of diabetic patient oneself.

Current case can be evaluated in the light of biopsycho-social aspects [22]. The first aspect is bioperspective. In comparison with Humalog mix 25, Xultophy can bring better glucose variability with only one injection. The second is psycho-perspective [23]. The case feels easy because of a less anxious episode for hypoglycemia. The third is social-perspective. Formerly, the case was limited to stay in a small area from home to working farm, because she was anxious for glucose control. With Xultophy, she can depart some distance for social activity. Her HbA1c for Feb, Mar, April 2021 was stable, which indicated the benefit of Xultophy.

In this article, some limitations are present. Only one case was reported with beneficial results of application for Xultophy. Future accumulation of adequate cases with Xultophy will be necessary. In actual diabetic practice, we always consider several aspects of the background of the patient [24].

In summary, a female T2DM patient showed satisfactory progress with Xultophy, associated with some discussion. This report includes an impressive perspective and will hopefully become a reference for future practice and research. 


\section{Funding}

There was no funding received for this paper.

\section{Competing Interests}

All authors have read and approved the final version of the manuscript. The authors have no conflicts of interest to declare.

\section{References}

[1] American Diabetes Association. Summary of Revisions: Standards of Medical Care in Diabetes-2021. Diabetes Care. 2021 Jan;44(Suppl 1):S4-S6. [PMID: 33298411]

[2] Davies MJ, D'Alessio DA, Fradkin J, Kernan WN, Mathieu C, Mingrone G, Rossing P, Tsapas A, Wexler DJ, Buse JB. Management of Hyperglycemia in Type 2 Diabetes, 2018. A Consensus Report by the American Diabetes Association (ADA) and the European Association for the Study of Diabetes (EASD). Diabetes Care. 2018 Dec;41(12):2669-701. [PMID: 30291106]

[3] Doyle-Delgado K, Chamberlain JJ, Shubrook JH, Skolnik N, Trujillo J. Pharmacologic Approaches to Glycemic Treatment of Type 2 Diabetes: Synopsis of the 2020 American Diabetes Association's Standards of Medical Care in Diabetes Clinical Guideline. Ann Intern Med. 2020 Nov 17;173(10):813-21. [PMID: 32866414] [4] American Diabetes Association. 10. Cardiovascular Disease and Risk Management: Standards of Medical Care in Diabetes-2021. Diabetes Care. 2021 Jan;44(Suppl 1):S125-S150. [PMID: 33298421]

[5] Atkins RC. Dr. Atkins' New Diet Revolution. New York, NY: Harper; 2009 Dec 29.

[6] Resch KL. "Du darfst"--brauchst aber nicht! [Dietary Intervention Randomized Controlled Trial (DIRECT) group: weight loss with a low-carbohydrate, Mediterranean, or low-fat diet]. Forsch Komplementmed. 2008 Dec;15(6):351-62. German. [PMID: 19156970]

[7] Feinman RD, Pogozelski WK, Astrup A, Bernstein RK, Fine EJ, Westman EC, Accurso A, Frassetto L, Gower BA, McFarlane SI, Nielsen JV, Krarup T, Saslow L, Roth KS, Vernon MC, Volek JS, Wilshire GB, Dahlqvist A, Sundberg R, Childers A, Morrison K, Manninen AH, Dashti HM, Wood RJ, Wortman J, Worm N. Dietary carbohydrate restriction as the first approach in diabetes management: critical review and evidence base. Nutrition. 2015 Jan;31(1):1-13. Erratum in: Nutrition. 2019 Jun;62:213. [PMID: 25287761]

[8] Ebe K, Ebe Y, Yokota S, Matsumoto T, Hashimoto M, Sakai Y. Low Carbohydrate diet (LCD) treated for three cases as diabetic diet therapy. Kyoto Medical Association Journal. 2004;51:125-29.

[9] Muneta T, Kawaguchi E, Nagai Y, Matsumoto M, Ebe K, Watanabe H, Bando H. Ketone body elevation in placenta, umbilical cord, newborn and mother in normal delivery. Glycat Stress Res. 2016 Sep 30;3(3):133-40.

[10] Bando H. Useful tips for actual low carbohydrate diet (LCD) with super-, standard-and petit-LCD methods. EC Nutrition. 2020 Apr 8;15(5):1-4.

[11] Ebe K, Bando H, Muneta T, Bando M, Yonei Y. Remarkable improvement of glucose variability by Sodium-glucose cotransporter 2 (SGLT2) inhibitors using continuous glucose monitoring (CGM). Diabetes Case Rep. 2019 Jan 28;4(1):1-5.

[12] American Diabetes Association. 9. Pharmacologic Approaches to Glycemic Treatment: Standards of Medical Care in Diabetes-2021. Diabetes Care. 2021 Jan;44(Suppl 1):S111-S124. [PMID: 33298420]

[13] Bando H. New era for useful add-on therapy (AOT) to diabetes by combined agents of insulin and glucagon-like peptide-1 receptor agonist (GLP-1RA). Int Med. 2020;2(5):264-66.

[14] Jiang Y, Liu J, Chen X, Yang W, Jia W, Wu J. Efficacy and Safety of Glucagon-Like Peptide 1 Receptor Agonists for the Treatment of Type 2 Diabetes Mellitus: A Network Meta-analysis. Adv Ther. 2021 Mar;38(3):1470-82. [PMID: 33582976]

[15] Novo Nordisk Inc. Xultophy 100/3.6 (insulin degludec and liraglutide) Injection. United States: U.S. Food and Drug Administration; 2016 Nov 21. Available from:

https://www.accessdata.fda.gov/drugsatfda_docs/nda /2016/208583Orig1soooTOC.cfm

[16] Homepage of Xultophy ${ }^{\circledR}$. Available from: https://www.xultophy10036pro.com/

[17] Cohen ND, Audehm R, Pretorius E, Kaye J, Chapman LH, Colagiuri S. The rationale for combining GLP-1 receptor agonists with basal insulin. Med J Aust. 2013 Aug 19;199(4):246-49. [PMID: 23984780]

[18] Marso SP, Daniels GH, Brown-Frandsen K, Kristensen P, Mann JF, Nauck MA, Nissen SE, Pocock S, Poulter NR, Ravn LS, Steinberg WM, Stockner M, Zinman B, Bergenstal RM, Buse JB; LEADER Steering 
Citation: Bando H, Ogawa H, Nagahiro S, Nakanishi M, Watanabe O. Satisfactory Control for Glucose Profile by Combined Agents of Xultophy with A Small Dose. Diab Res Open Access. 2021 Jun o8;3(2):23-29.

Case Report

Committee; LEADER Trial Investigators. Liraglutide and Cardiovascular Outcomes in Type 2 Diabetes. N Engl J Med. 2016 Jul 28;375(4):311-22. [PMID: 27295427]

[19] Taybani Z, Bótyik B, Katkó M, Gyimesi A, Várkonyi T. Simplifying Complex Insulin Regimens While Preserving Good Glycemic Control in Type 2 Diabetes. Diabetes Ther. 2019 Oct;10(5):1869-78. [PMID: 31347100]

[20] Price H, Blüher M, Prager R, Phan TM, Thorsted BL, Schultes B; EXTRA study group. Use and effectiveness of a fixed-ratio combination of insulin degludec/liraglutide (IDegLira) in a real-world population with type 2 diabetes: Results from a European, multicentre, retrospective chart review study. Diabetes Obes Metab. 2018 Apr;20(4):954-62. [PMID: 29205856]
[21] Kato Y, Bando H, Yamashita H, Yada S, Tokuhara $\mathrm{S}$, Tokuhara H, Mutsuda T. Impressive clinical course of diabetic patient with various medical problems and remarkable improvement by insulin degludec and liraglutide (Xultophy). MOJ Clin Med Case Rep. 2020 Apr 30;10(2):48-51.

[22] Bando H. Direction for Basal Insulin Therapy by Once Daily Injection in the Clinical Practice. Diab Res Open Access. 2021 Feb 17;3(1):11-15.

[23] van Duinkerken E, Moreno AB, Eto FN, Lotufo P, Barreto SM, Giatti L, Viana MC, Nunes MA, Chor D, Griep RH. Biopsychosocial factors associated with a current depressive episode in diabetes: the ELSA-Brasil study. Diabet Med. 2020 Oct;37(10):1742-51. [PMID: 32580244]

[24] Novo Nordisk. Xultophy FDA Approval History. Drugs.com; 2016 Nov 21. Available from: https://www.drugs.com/history/xultophy.html 